\title{
Removal of Crystal Violet and Eriochrome Black T Dyes from Aqueous Solutions by Magnetic Nanoparticles Biosynthesized from Leaf Extract of Fraxinus Chinensis Roxb
}

\author{
Imran Ali ${ }^{1,2}$, Changsheng Peng ${ }^{1-3 *}$, Zahid M. Khan ${ }^{4}$, Muhammad Sultan ${ }^{4 * *}$, Iffat Naz, \\ Mohsin Ali ${ }^{6}$, Hafiz U. Farid ${ }^{4}$, Muhammad H. Mahmood ${ }^{4}$, Rameez Ahsen ${ }^{4}$ \\ ${ }^{1}$ Department of Environmental Engineering, College of Environmental Science and Engineering, \\ Ocean University of China, Qingdao, China \\ ${ }^{2}$ The Key Lab of Marine Environmental Science and Ecology, Ministry of Education, \\ Ocean University of China, Qingdao, China \\ ${ }^{3}$ School of Environmental and Chemical Engineering, Zhaoqing University, Zhaoqing, China \\ ${ }^{4}$ Department of Agricultural Engineering, Bahauddin Zakariya University, Multan, Pakistan \\ ${ }^{5}$ Department of Biology, Qassim University, Buraidah, Kingdom of Saudi Arabia \\ ${ }^{6}$ Department of Environmental Engineering, Middle East Technical University, Ankara, Turkey
}

Received: 4 January 2018

Accepted: 25 March 2018

\begin{abstract}
In the present research, a "green" recipe was used to produce innovative phytogenic magnetic nanoparticles (PMNPs) from leaf extract of Fraxinus chinensis Roxb without employing any additional toxic surfactants as capping agents. The convenient reaction between metal salt solution and plant biomolecules occurred within a few minutes by color changes from pale green to intense black, hinting at the production of magnetic nanoparticles (MNPs). The formation of PMNPs was verified by employing different techniques such as UV-visible spectrophotometry, Fourier transform infrared spectroscopy (FTIR), powder X-ray diffraction (XRD), scanning electron microscope (SEM) and energy dispersive X-ray (EDX). The fabricated PMNPs were further utilized as a catalyst for removing toxic dyes, i.e., Crystal violet (CV) and Eriochrome black T (EBT) from aqueous solutions in the presence of hydrogen peroxide $\left(\mathrm{H}_{2} \mathrm{O}_{2}\right)$. The concentrations of $\mathrm{CV}$ and EBT were calculated using ultraviolet-visible (UV-vis) spectroscopy throughout all the experiments. The results indicated that PMNPs showed $>95 \%$ removal of both dyes within 10 min of contact time over a wide range of concentration, $10-300 \mathrm{mg} / \mathrm{L}$. The degradation kinetics were also investigated using first- and second-order rate equations, and the results indicated that kinetic data of both $\mathrm{CV}$ and EBT followed first-order degradation rate. Moreover, the removal efficiency of the fabricated PMNPs was also
\end{abstract}

*e-mail: pcs005@ouc.edu.cn

**e-mail: muhammadsultan@bzu.edu.pk 
compared with chemically synthesized magnetic nanoparticles (CSMNPs), and the results indicated that our fabricated PMNPs were more effective in terms of extent and speed to remove dyes. Finally, we have also proposed a possible removal mechanism. Altogether, the developed "green" recipe can easily be implemented to produce potentially biocompatible and non-toxic PMNPs for treatment of wastewater and can also easily be employed in low-economy countries.

Keywords: Fraxinus chinensis Roxb, plant leaf extract, phytogenic magnetic nanoparticles, Crystal violet, Eriochrome black T

\section{Introduction}

Water pollution levels of natural streams is increasing day by day due to the discharge of toxic dyes and aromatic pollutants from different industries like leather, cosmetics, textile, food and pharmaceuticals, etc. [1-5]. Out of all industries, the textile industry mainly uses toxic dyes for coloring their products and discharging a huge amount of toxic dyes contaminated into the natural/aquatic environment without proper treatment. Thus, worldwide the annual production of dyes is approximately 0.7 million tons and the textile industry generates huge quantities of complex chemical substances as waste, including dyes in the form of wastewater in various stages of textile manufacturing and processing. On average, to produce $1 \mathrm{~kg}$ of textile, $\sim 200 \mathrm{~L}$ of water is consumed and an average-sized textile mill with a production of about $8000 \mathrm{~kg}$ of fabric per day consumed about 1.6 million $\mathrm{L}$ water. Moreover, on average, the reported concentrations of biological oxygen demand $\left(\mathrm{BOD}_{5}\right)$, total solids (TS) and color in textile wastewater are about $6000,1560 \mathrm{mg} / \mathrm{L}$ and 1450-4750 ADMI, respectively [6-8]. Importantly, these toxic dyes are creating harmful effects and diseases in residential communities, i.e., allergies, jaundice, heart defects, skin irritation, and tumors. In addition, these toxic dyes are destroying aquatic life by creating a hindrance to penetration of proper sunlight for photosynthesis due to having visible color [9-11]. Therefore, the removal and treatment of these dyes is an important area of applied research for wastewater treatment experts to keep natural water environments safe and clean.

The conventional biological methods (such as trickling filter, activated sludge system, membrane bioreactors, etc.) and chemical treatment methods (such as coagulation, flocculation, electrochemical oxidation, etc.) are often considered ineffective and expensive for the treatment and handling of these toxic dyes, because these toxic dyes usually show resistance to aerobic biodegradation, heat, oxidizing agents and light [3, 1, 12]. In contrast, adsorptive treatment is normally considered an alternate option to treat such toxic and aromatic pollutants because of their design simplicity, treatment flexibility and insensitivity to toxicity. For this purpose, the removal performance of different adsorbents, including agricultural wastes - such as banana pith, orange peel [13], rice husk [14], peanut hull [15], coir pith [16], pinewood and jute fiber [17] - activated carbon and its different composites have been well documented. For instance, Sivaraj et al. [13] used orange peel as an adsorbent to remove Acid violet 17 from aqueous solutions and reported a maximum of $87 \%$ removal and $19.88 \mathrm{mg} / \mathrm{g}$ adsorptive capacity at an adsorbent dose of $600 \mathrm{mg} / 50 \mathrm{~mL}$ using $10 \mathrm{mg} / \mathrm{L}$ of initial dye concentration. Similarly, Gong et al. [15] reported the use of powdered peanut hull as an adsorbent to remove three anionic dyes such as amaranth (Am), sunset yellow (SY) and fast green FCF (FG). The findings of this study revealed that a maximum of 14.9, 13.9 and $15.60 \mathrm{mg}$ dye per gram of the adsorptive capacity was achieved for Am, SY and FG, respectively, using adsorbent dose of $5.0 \mathrm{~g} / \mathrm{L}$. In another study jute fiber carbon (JFC) was used as a low-cost adsorbent material and it showed theremoval of $92.06 \%$ of eosin yellow, $87.65 \%$ of malachite green (MG) and $95.93 \%$ of crystal violet from aqueous solutions [17]. However, certain issues such as low removal capacity and lack of reusability are hindering its execution for real applications.

Hence, in order to handle these issues and improve their performance, nanostructured metal oxide and its composites are getting great research attention due to their easy fabrication, low cost requirement, high stability, high magnetic permeability and ease in separation from the final effluents by applying an external magnetic force [18-19]. They have been utilized for the removal and degradation of toxic and aromatic pollutants from wastewaters due to their unique physical, chemical and catalytic characteristics. For example, Luo and Zhang [19] fabricated cellulose-based magnetic beads by incorporating activated carbon (AC) for the removal of methyl orange (MO) and methylene blue (MB) from aqueous solution. The findings depicted more than $95 \%$ removal of both dyes observed within the contact time of $180 \mathrm{~min}$ and prepared material separated from solution just by applying a magnet, and reused for at least 3 times by retaining removal efficiency above $95 \%$. Similarly, green magnetic nanoparticles were also employed for the removal of toxic dyes as explained in detail in the author's previously published report [2]. Until now, different methods (hydrothermal process, electrochemical route, chemical co-precipitation, solgel technique, and micro-emulsion technique) have been documented in literature to fabricate/synthesie these metal oxide nanoparticles [3-5]. However, certain 
aspects such as the requirement of high temperature and pressure, involvement of hazardous and toxic reducing and capping agents to stabilize the size and composition of magnetic nanoparticles, and the harsh reaction conditions and long reaction time are the main disadvantages of employing these fabrication methods [2-5]. In addition, the aggregation of these nanoparticles into chain-like structures was one of the well-known characteristics, which was responsible to reduce its surface area-to-volume ratio [20]. However, it is also worth mentioning here that the stability of these nanoparticles against aggregation can be enhanced by utilizing organic surfactants or through the use of different capping agents [21].

Another approach that can serve this goal is to fabricate iron oxide nanoparticles using green nanotechnology [22]. Green nanotechnology is getting great research interest because of its low cost, involvement of plant bio-molecules as reducing and capping agents instead of toxic and hazardous chemicals, and requirement of low temperature and pressure to fabricate metal oxide NPs [23]. In addition, green fabrication would impart steric stabilization of iron NPs against aggregation and help to minimize the concerns related to the use of toxic and hazardous chemicals (sodium borohydride, $\mathrm{NaBH}_{4}$ ) as a reducing agent because this chemical is famous for its corrosiveness and flammability. Recently, different kinds of plant leaves, flowers and fruit peels have been employed for the fabrication of metal oxide NPs, and their adsorptive and catalytic performance have also been documented in the literature [4]. Moreover, it can be observed from the published reports that mostly green magnetic nanoparticles (MNPs) have been used for the adsorptive removal of heavy metals ions $(\mathrm{Pd}, \mathrm{Cd}, \mathrm{Hg}, \mathrm{As}$ and $\mathrm{Cr}$ ) from aqueous solutions [24-30]. However, very limited literature is available to address its catalytic performance to degrade toxic dyes and aromatic pollutants [31-33]. For instance, Buazar et al. [31] conducted a study to remove an organic methylene blue (MB) contaminant from wastewater at room temperature using green MNPs fabricated by homemade starch-rich potato extract and reported 100\% removal of $\mathrm{MB}$ from solutions within the contact time of $30 \mathrm{~min}$. Similarly, another study showed malachite green (MG) dye 96\% removal efficiency within the contact time of $60 \mathrm{~min}$ at $50 \mathrm{mg} / \mathrm{L}$ and $298 \mathrm{~K}$ by using green iron NPs synthesized from green tea extract [33]. Recently, Prasad et al. [32] investigated the degradation of Methyl orange (MO) dye from aqueous solution using $\mathrm{Fe}_{3} \mathrm{O}_{4}$ magnetic nanoparticles (MNPs) fabricated from extract of Pisum sativum peels (PS), and reported $96 \%$ removal within the contact time of $60 \mathrm{~min}$ at concentration of $100 \mathrm{mg} / \mathrm{L}$. Therefore, in the present study, we employed our fabricated green MPNs for the catalytic degradation of cationic $\mathrm{CV}$ and anionic EBT toxic dyes to investigate the influence of different kinds of dyes on the degradation performance by green MNPs.
Herein, we fabricated for the first time, phytogenic magnetic nanoparticles (PMNPs) from leaf extract of Fraxinus chinensis Roxb as a reducing and capping agent for the degradation of toxic dyes. The common name of F. chinensis Roxb plant is Chinese ash. Its leaves have been used in traditional Chinese medicine (TCM) for dysentery disorders. The genus is widespread across much of Europe, Asia and North America. Its growth rate in the city of Qingdao, China is very high and its leaves are easily available without any costs or/ nominal price. The main objectives of the current study was (i) to fabricate PMNPs using leaf extract of $F$. chinensis Roxb; (ii) to confirm the fabrication by using different techniques such as UV-visible spectrophotometry, fourier transforms infrared spectroscopy (FT-IR), powder X-ray diffraction (XRD), scanning electron microscope (SEM) and energy dispersive X-ray (EDX); (iii) to investigate the effectiveness of PMNPs to remove toxic dyes (i.e., $\mathrm{CV}$ and $\mathrm{EBT}$ ) from aqueous solutions in the presence of $\mathrm{H}_{2} \mathrm{O}_{2}$; and (iv) to compare the performance of PMNPs with chemically synthesized magnetic nanoparticles (CSMNPs) in terms of extent and speed to remove toxic dyes by fitting experimental data into first- and second-order rate equations.

\section{Materials and Methods}

\section{Materials and Chemicals}

Various different chemicals - viz., Ferric chloride hexahydrate $\left(\mathrm{FeCl}_{3} \cdot 6 \mathrm{H}_{2} \mathrm{O}\right)$, ferrous sulfate $\left(\mathrm{FeSO}_{4} \cdot 7 \mathrm{H}_{2} \mathrm{O}\right)$, sodium hydroxide $(\mathrm{NaOH})$, tripyridyltriazine (TPTZ, HPLC grade), acetate buffer, $\mathrm{HCl}$, ferric trichloride, potassium ferricyanide, copper sulfate, $\mathrm{Na}_{2} \mathrm{CO}_{3}, \mathrm{MgSO}_{4}$, crystal violet $\left(\mathrm{C}_{25} \mathrm{H}_{30} \mathrm{ClN}_{3}\right), \mathrm{NaBH}_{4}$ (Aldrich, 99\%), Eriochrome black $\mathrm{T}\left(\mathrm{C}_{20} \mathrm{H}_{12} \mathrm{~N}_{3} \mathrm{O}_{7} \mathrm{SNa}\right)$ (Aldrich, 99\%), ethanol $\left(\mathrm{C}_{2} \mathrm{H}_{5} \mathrm{OH}\right)$, gallic acid (Merck, 99.9\%), $\mathrm{H}_{2} \mathrm{O}_{2}$ (Aldrich, 30\%), ethanol $\left(\mathrm{C}_{2} \mathrm{H}_{5} \mathrm{OH}\right)$, and gallic acid (Merck, 99.9\%) - were used without further purification in the present research investigation. Deionized water (DI) was obtained from the Qingdao Water Purification Agency to make all aqueous solutions. For making CV and EBT stock solution (1000 mg/L), $1000.0 \mathrm{mg}$ powder chemical of CV and EBT was added in $1000 \mathrm{~mL}$ DI water in the volumetric flask. Furthermore, different concentrations of dye solutions were prepared using dilution method $\left(\mathrm{C}_{1} \mathrm{~V}_{1}=\mathrm{C}_{2} \mathrm{~V}_{2}\right)$ by keeping the volume of dyes solution constant $(50 \mathrm{~mL})$. The $\mathrm{pH}$ adjustments were made by using $0.1 \mathrm{~mol} / \mathrm{L} \mathrm{NaOH}$ and $\mathrm{HCl}$ solution throughout all the experiments, wherever needed.

Biosynthesis of Phytogenic Magnetic Nanoparticles (PMNPs)

\section{Selection of Fraxinus chinensis Roxb}

For the fabrication of PMNPs, the leaves of ' $F$. chinensis Roxb' were selected and were washed 
with DI water to remove impurities (dust), then dried under sunlight for at-least 10 days and further kept in a drying oven for $6 \mathrm{~h}$ at $85^{\circ} \mathrm{C}$ to reduce moisture. Then the dried plant leaves were chopped into small pieces manually and passed through a $2 \mathrm{~mm}$ sieve. The final product was collected and stored for further use in the preparation of extract.

\section{Evaluating the Reducing Capacity of the Extracts}

The reducing ability of the extract was investigated using ferric reducing antioxidant power (FRAP) assay and color development tests [34]. During the FRAP assay, the ability of the extract to reduce $\mathrm{Fe}^{+3}$ to $\mathrm{Fe}^{+2}$ is measured at absorbance $(\lambda=593 \mathrm{~nm})$ by producing blue complex with tripyridyltriazine (TPTZ). The FRAP reagent was made by using $20 \mathrm{mM}$ of $\mathrm{FeCl}_{3}$ solution, $300 \mathrm{mM}$ of acetate buffer and $10 \mathrm{mM}$ of TPTZ solution in $\mathrm{HCl}$ at a 1:1:10 ratio. The absorbance of samples containing $800 \mu \mathrm{L}$ of FRAP reagent, $60 \mu \mathrm{L}$ of $\mathrm{H}_{2} \mathrm{O}$, and $20 \mu \mathrm{L}$ of extract was determined at $\lambda=593 \mathrm{~nm}$ using a UV-vis spectrophotometer. The FRAP reagent was kept at room temperature $\left(25^{\circ} \mathrm{C}\right)$ throughout the experiments [35]. The standard calibration curve for this test was also designed using six $\mathrm{Fe}^{+2}$ standards with concentration range between 100 and 1000 $\mu \mathrm{mol} / \mathrm{L}$ ( $r>0.999)$, which was further used in extract optimization study.

\section{Total Phenolic Content (TPC)}

The presence of phenolic compounds is often considered an important element in the formation of green MNPs, because it has been reported that phenolic compounds with $-\mathrm{OH}$ groups in the orhoposition assist in the reduction and construction of green magnetic nanoparticles [36]. For this purpose, the Folin-Ciocalteu method was employed to investigate TPC in the extract using gallic acid as the standard [34]. A dilution sample was prepared containing extract $(20 \mu \mathrm{L})$ and $40 \mu \mathrm{L}$ of pure DI water. Thereafter, Folin-Ciocalteu reagent $(100 \mu \mathrm{L})$ was added and mixed. After mixing of $5 \mathrm{~min}, 300 \mathrm{~mL}$ of $\mathrm{Na}_{2} \mathrm{CO}_{3}$ solution was injected and permitted to stand for $15 \mathrm{~min}$. Finally, the absorbance of the sample was determined at $\lambda=$ by UV-vis spectrophotometer. The results of TPC were stated as milligrams of gallic acid equivalent (GAE) per gram of dry weight.

\section{Fabricating Phytogenic Magnetic Nanoparticles} (PMNPs)

The optimized extraction condition and fabrication protocol was selected and employed for the fabrication of PMNPs. Briefly, for preparing extract, $10 \mathrm{~g}$ of leaf powder of $F$. chinensis Roxb was added in $80 \mathrm{~mL}$ of DI and the mixture was heated at $80^{\circ} \mathrm{C}$ for $90 \mathrm{~min}$.
The $\mathrm{pH}$ of the solution was maintained at 3 using $0.1 \mathrm{~mol} / \mathrm{L} \mathrm{NaOH}$ and $\mathrm{HCl}$ solution. Thereafter, (1:1) metal solution (MS) ratio of $\left(\mathrm{Fe}^{+2}: \mathrm{Fe}^{+3}\right)$ was prepared using $50 \mathrm{~mL}$ DI. After this, 50:50 (vol./vol.) ratio of MS and extract was prepared and boiled at $80^{\circ} \mathrm{C}$ with continues stirring (at $100 \mathrm{rpm}$ ) by a magnetic stirrer heater for $60 \mathrm{~min}$. The $\mathrm{pH}$ of the mixture was adjusted at 12 by adding $0.1 \mathrm{~mol} / \mathrm{L} \mathrm{NaOH}$ solution drop-wise. The mixture color was changed from reddish brown to black, indicating the formation of PMNPs. Then the mixture was allowed to stand for $60 \mathrm{~min}$ and the black color precipitations were centrifuged for $20 \mathrm{~min}$ at $8000 \mathrm{rpm}$, then the supernatant was vacuum-filtered through a $0.22 \mu \mathrm{m}$ filter paper. The black powder was collected and washed twice with $50 \mathrm{~mL}$ of ethanol solution. The final product was again vacuum-filtered through a $0.22 \mu \mathrm{m}$ filter paper. Lastly, the collected black powder was kept in a drying oven for at least $120 \mathrm{~min}$ at $80^{\circ} \mathrm{C}$. The obtained PMNPs were further employed in degradation experiments.

\section{Fabricating Chemically Synthesized Magnetic Nanoparticles (CSMNPs)}

For performance comparison, the CSMNPs were fabricated by chemical co-precipitation method using sodium borohydrate $\left(\mathrm{NaBH}_{4}\right)$ as a reducing agent. Briefly, first MS 2:1 ratio of $\mathrm{FeCl}_{3} \cdot 6 \mathrm{H}_{2} \mathrm{O}(18.965 \mathrm{~g})$ and $\mathrm{FeSO}_{4} .7 \mathrm{H}_{2} \mathrm{O}(9.563 \mathrm{~g})$ was added in $50 \mathrm{~mL}$ solution of $(90 \%)$ ethanol absolute and the mixture was boiled at $80^{\circ} \mathrm{C}$ with continuous stirring $(100 \mathrm{rpm})$ by a magnetic stirrer heater. Meanwhile, $80 \mathrm{~mL}$ of $\mathrm{NaBH}_{4}$ solution was prepared separately using $8.23 \mathrm{~g}$ of $\mathrm{NaBH}_{4}$. Thereafter, $\mathrm{NaBH}_{4}$ solution was injected drop-wise (25-45 drop/min) in the first solution. The black color precipitations appeared quickly, when the first drop of $\mathrm{NaBH}_{4}$ solution was injected. Thereafter, $\mathrm{NaBH}_{4}$ solution was injected drop-wise until metal solution color was completely changed from reddish yellow to black. The mixture was allowed to heat for $1.0 \mathrm{~h}$. Finally, after settling for $1.0 \mathrm{~h}$, the mixture was vacuumfiltered through a $0.22 \mu \mathrm{m}$ filter paper. The black powder was collected and washes twice with $50 \mathrm{~mL}$ of ethanol solution. The final product was again vacuum-filtered through a $0.22 \mu \mathrm{m}$ filter paper. Thereafter; the collected black powder was kept in a drying oven at $80^{\circ} \mathrm{C}$ for $60 \mathrm{~min}$. These CSMNPs were further employed for degradation experiments.

\section{Characterization}

\section{Characterization of Plant Extract}

Elemental contents $(\mathrm{C}, \mathrm{N}, \mathrm{S}$ and $\mathrm{H})$ and heavy metals content of plant leaves extract were determined by using elemental analyzer (EA, Vario EL cube, German) and atomic absorption spectrometry (Solar M6, Thermo Elemental, USA), respectively. 


\section{Characterization of Phytogenic Magnetic Nanoparticles (PMNPS)}

The fabricated PMNPs were characterized using FTIR, XRD, SEM and EDX/S, techniques. A Bruker Vertex 70 was used for FTIR analysis and the probable bio-molecules present in the plant extract were identified, which were responsible for the reduction and stabilization of PMNPs. A Philips Electronic Instrument was employed for the XRD analysis and the crystalline shape of the fabricated PMNPs and CSMNPs was identified. The fabricated PMNPs and CSMNPS samples were washed completely with ethanol prior to analysis in order to minimize the $\mathrm{NaCl}$ content and other impurities that crystallized during the fabrication process. The samples were scanned within $2 \theta$ range of $20-70^{\circ}$. The morphologies of the fabricated CSMNPs and PMNPs were scrutinized by scanning electron microscopy (SEM) and the elemental content was analyzed by energy dispersive spectroscopy EDS/X (SEM/EDX, JSM-6700F).

\section{Batch Experiments}

For the removal investigation, batch experiments were performed by shaking Erlenmeyer flasks in a thermostat water bath under atmospheric pressure and room temperature $\left(25 \pm 2^{\circ} \mathrm{C}\right)$. A fixed amount of $0.500 \mathrm{~g}$ powdered PMNPs and CSMNPs was added in each dye solution along-with $2 \mathrm{~mL}$ of $(30 \%) \mathrm{H}_{2} \mathrm{O}_{2}$ solution and the shaking speed was kept constant at $100 \mathrm{rpm}$ for all the experiments. The $\mathrm{pH}$ of the dye solution was adjusted at 6.5 using $0.1 \mathrm{~mol} / \mathrm{L} \mathrm{NaOH}$ and $\mathrm{HCl}$ solution, similar to real acid dyeing effluents, unless otherwise stated. For checking the influence of dyes concentration on the removal performance, the concentration of the dyes solution was varied from $10-300 \mathrm{mg} / \mathrm{L}$ in a $100 \mathrm{~mL}$ Erlenmeyer flask (where the total volume of the dye solution was $50 \mathrm{~mL}$ along with $2 \mathrm{~mL}$ of $30 \% \mathrm{H}_{2} \mathrm{O}_{2}$ solution). At the end of the each experiment, the PMNPs and CSMNPs were separated by using a magnet, and the final solutions were vacuum-filtered through $0.45 \mu \mathrm{m}$ filter paper. The final dye concentration values were determined using UV-vis spectrophotometer and samples absorbance readings were calculated at $\lambda_{\max }=585 \mathrm{~nm}$ for Crystal violet (CV) and $\lambda_{\max }=623 \mathrm{~nm}$ for Eriochrome black $\mathrm{T}$ (EBT). The predetermined standard calibration curves were employed to measure the actual dyes concentration. All the experiments were performed in triplicate and the average values were used to make the final discussion. Finally, the removal efficiency at different dosages and dye concentrations was calculated as:

$$
\text { Removal efficiency (\%) }=\frac{C_{o}-C_{t}}{C_{o}} \times 100 \%
$$

...where $\mathrm{C}_{\mathrm{o}}(\mathrm{mg} / \mathrm{L})$ is the initial dye concentration in the solution and $\mathrm{C}_{\mathrm{t}}(\mathrm{mg} / \mathrm{L})$ is the final concentration dye solution at different time intervals.

For kinetic studies, a fixed amount of $0.500 \mathrm{~g}$ powdered PMNPs and CSMNPs were added in an Erlenmeyer flask containing $2 \mathrm{~mL}$ of $30 \% \quad \mathrm{H}_{2} \mathrm{O}_{2}$ solution and $48 \mathrm{~mL}$ of $300 \mathrm{mg} / \mathrm{L}$ dye solutions. The mixture was placed in a thermostat water bath under atmospheric pressure and room temperature $\left(25 \pm 2^{\circ} \mathrm{C}\right)$ by adjusting shaking speed at $100 \mathrm{rpm}$. The aqueous dyes concentration was determined at the end of 5,10 , $15,20,30,60,120,180,240,300$ and $360 \mathrm{~min}$. At the end of the each experiment, PMNPs and CSMNPs were separated using a simple magnet and the final solutions were vacuum-filtered using $0.45 \mu \mathrm{m}$ filter paper. Then the UV-vis absorbance values were measured using a UV-Vis spectrophotometer. All the kinetic experiments were conducted in triplicate and the average values were put in the kinetic equations given below [20]:

Fist-order rate equation

$$
\ln \left(\frac{C_{t}-C_{e}}{C_{o}-C_{e}}\right)=-k_{t} t
$$

Second-order rate equation

$$
\frac{1}{C_{t}-C_{e}}-\frac{1}{C_{o}-C_{e}}=k_{2} t
$$

...where $\mathrm{C}_{\mathrm{o}}(\mathrm{mg} / \mathrm{L})$ is the initial concentration of the dye solution, $\mathrm{C}_{\mathrm{t}}(\mathrm{mg} / \mathrm{L})$ and $\mathrm{C}_{\mathrm{e}}(\mathrm{mg} / \mathrm{L})$ are the concentrations at time (t) and equilibrium, and $\mathrm{k}_{1}$ and $\mathrm{k}_{2}$ are the rate constant for $1^{\text {st }}$ and $2^{\text {nd }}$ equations.

\section{Results and Discussion}

\section{Characterization of Leaf Extracts of $F$. chinensis Roxb}

The main objective of the extract characterization was to examine the safe and clean green synthesis of PMNPs by investigating the elemental contents and heavy metals content. The surplus amount of heavy metals can generate contamination in the plant leaf extract. In addition, it has been reported that by knowing elemental contents $(\mathrm{C}, \mathrm{H}, \mathrm{N}$ and $\mathrm{S})$, the probability regarding the presence of certain organic compounds can be supposed. In the present study, the elemental contents of $F$. chinensis Roxb were C (38.6\%), $\mathrm{H}(4.99 \%), \mathrm{S}(0.39 \%)$ and $\mathrm{N}(4.38 \%)$. Hence, these results indicated that the presence of $\mathrm{N}$ and $\mathrm{S}$ might be due to protein, chlorophyll, nucleic acids, cysteine, cystine and methionine in the plant leaf extract. In contrast, negligible contents of heavy metals $\mathrm{Cr}$ $(0.011 \mathrm{mg} / \mathrm{L}), \mathrm{Fe}(0.06 \mathrm{mg} / \mathrm{L}), \mathrm{Pb}(0.07 \mathrm{mg} / \mathrm{L}), \mathrm{Co}$ $(0.013 \mathrm{mg} / \mathrm{L}), \mathrm{Cd}(0.001 \mathrm{mg} / \mathrm{L})$, and $\mathrm{Zn}(0.25 \mathrm{mg} / \mathrm{L})$ 


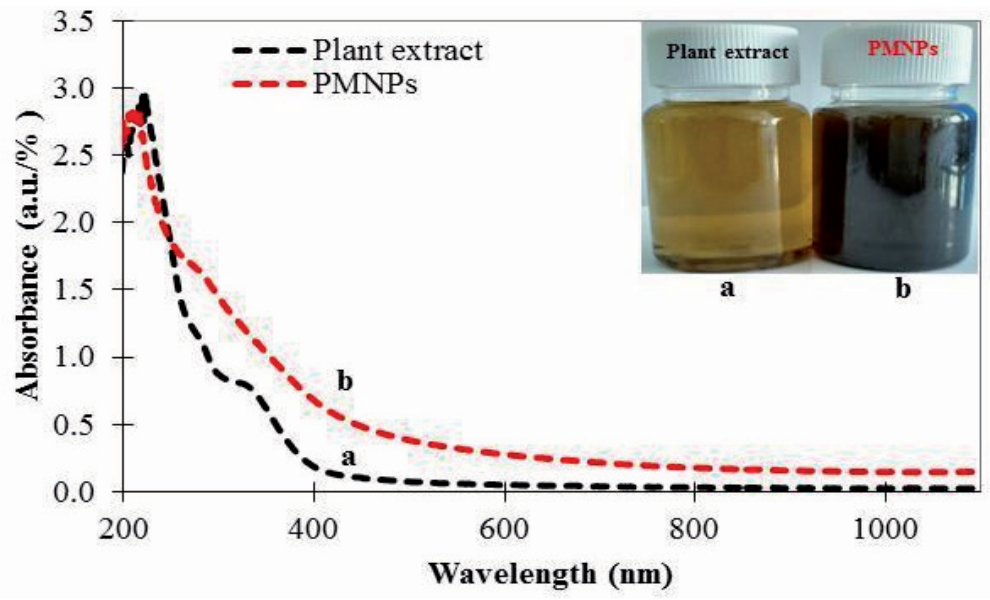

Fig. 1. UV-vis spectra of F. chinensis Roxb leaf extract a) and phytogenic magnetic nanoparticles (PMNPs) b); inset shows the photographic interpretation of the reaction [34]

were observed in the extract. Our finding indicated that organic compounds were the main component of this extract and only negligible amounts of heavy metals contents were observed, thereby confirming safe and green fabrication of PMNPs. Furthermore, it was also noticed that at optimized conditions, higher antioxidant capacity $\left(0.047 \quad \mathrm{Fe}^{+2} \mathrm{mmol} / \mathrm{L}\right)$ and TPC $(83.3 \pm 5.1 \mathrm{GAE} \mathrm{mg} / \mathrm{g} \mathrm{DW})$ was measured by FRAP and the Folin-Ciocalteu method. These findings depicted that leaf extract had a high presence of reducing compounds, which could produce higher yield of PMNPs. Numerous studies have also explained this fact that if extracts have higher antioxidant capacity and TPC, then it will show higher potential in producing PMNPs through the reduction of metal ions [35].

\section{Characterization of Phytogenic Magnetic Nanoparticles (PMNPs)}

The fabrication of PMNPs was first confirmed through change in color from dark green to black using UV-vis absorption spectra [34]. Fig. 1 illustrates that the reaction between metal salt and plant extract was instantaneous and the color of the reaction solution changed from dark green to black (inset of Fig. 1) [34]. This fabrication might be explained in that a variety of plant bio-molecules (polyphenols) played a major role in the reduction of metal ions and sufficiently stabilized the $\mathrm{Fe}_{3} \mathrm{O}_{4}$ NPs to fabricate PMNPs under alkaline conditions ( $\mathrm{pH}$ 12). Thus, after the reaction, it can be seen that the UV spectra of fabricated PMNPs had broad absorption at higher wavelength than plant extract, and there was no sharp absorption at lower wavelengths (Fig. 1(a, b)). The formation of PMNPs or the reactions that might occur in the fabrication of PMNPs are as shown in Equations:

$$
\begin{gathered}
\mathrm{FeSO}_{4} \cdot 7 \mathrm{H}_{2} \mathrm{O}+2 \mathrm{FeCl}_{3} \cdot 6 \mathrm{H}_{2} \mathrm{O}+8 \mathrm{NaOH} \rightarrow \\
\mathrm{Fe}_{3} \mathrm{O}_{4}+6 \mathrm{NaCl}+(\mathrm{Na})_{2} \mathrm{SO}_{4}+17 \mathrm{H}_{2} \mathrm{O}
\end{gathered}
$$

$$
\begin{gathered}
\mathrm{Fe}_{3} \mathrm{O}_{4}+\text { leaves extract }+17 \mathrm{H}_{2} \mathrm{O} \rightarrow \\
\text { leaves extract- } \mathrm{Fe}_{3} \mathrm{O}_{4} / \mathrm{PMNPs}
\end{gathered}
$$

Fig. 2 illustrates the FTIR spectra of leaf extract and fabricated PMNPs. The FTIR spectra are revealing different peaks in the spectral range of 500-4000 $\mathrm{cm}^{-1}$. These peaks were attributed to the probable presence of plant bio-molecules at the surface of PMNPs. Fig. 2 showed that the board absorptions at $3454 \mathrm{~cm}^{-1}$ mainly represent the $\mathrm{O}-\mathrm{H}$ stretching vibrations (polyphenolic group) and it was shifted to $3460 \mathrm{~cm}^{-1}$ (Fig. 2b). Its breadth might be due to the formation of intra and intermolecular hydrogen bonds [31]. The peaks at 2935 and $2893 \mathrm{~cm}^{-1}$ represent O-H stretching and $\mathrm{C}-\mathrm{H}$ stretching vibrations of carboxylic acid, alcohol or alkene (Fig. 2b). A very strong peak at $1662 \mathrm{~cm}^{-1}$ revealed the presence of $\mathrm{C}=\mathrm{O}$ stretching or $\mathrm{C}=\mathrm{C}$ stretching vibration of acid derivatives and was shifted to $1639 \mathrm{~cm}^{-1}$. These peaks indicated the sign of physisorbed or chemisorbed $\mathrm{H}_{2} \mathrm{O}$ on the PMNPs [31, 32]. A slight board absorption peak at $1163 \mathrm{~cm}^{-1}$ indicated the $\mathrm{C}-\mathrm{O}$ stretching vibration of ester and it was shifted to $1114 \mathrm{~cm}^{-1}$, indicating the $\mathrm{C}-\mathrm{O}$ stretching vibration of aliphatic ether or bond of glucose ring in the extract. Moreover, after the reduction of metals salt solution, the prompt decrease in the intensity at 1662 and $1163 \mathrm{~cm}^{-1}$ implies the major role of the $\mathrm{OH}$ group in this reduction process [20, 32]. Finally, a strong absorption band at $585 \mathrm{~cm}^{-1}$ indicates or can be attributed to the characteristic band of Fe-O, which suggests the formation of $\mathrm{Fe}_{3} \mathrm{O}_{4} \mathrm{NPs}$ or PMNPs (as reported previously by Prasad et al. [32]. Therefore, FTIR results verified the capping and involvement of plant bio-molecules (polyphenol, carboxyl, glucose, alkene, primary amine, ester, aliphatic and ether) on the surface of PMNPs in the shape of $-\mathrm{OH}, \mathrm{C}-\mathrm{H}, \mathrm{C}-\mathrm{O}$ functional groups. In addition, the FTIR results also verified the results obtained from color development tests (as discussed in the extract characterization section). 

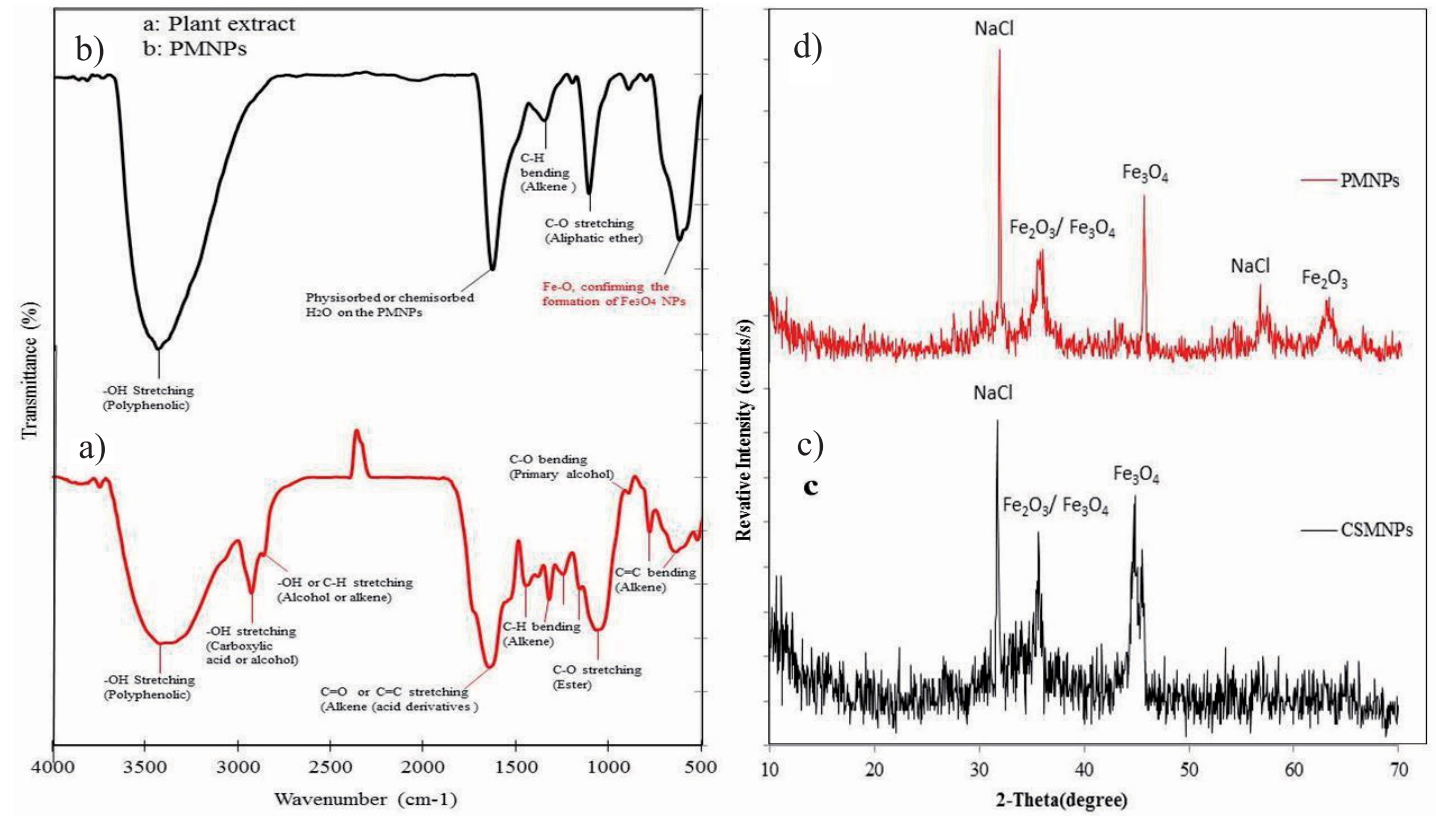

Fig. 2. Fourier transform infrared (FTIR) spectrum of a) plant extract and b) fabricated phytogenic magnetic nanoparticles (PMNPs); and the powder XRD patterns of c) chemically synthesized magnetic nanoparticles (CSMNPs) and d) PMNPs.

Fig. 2d) shows the XRD pattern of the PMNP structure. The reflections in the XRD diagram were found to belong to iron oxide or magnetite $\left(\mathrm{Fe}_{3} \mathrm{O}_{4}\right)$, ferric oxide or hematite $\left(\mathrm{Fe}_{2} \mathrm{O}_{3}\right)$, in addition to $\mathrm{NaCl}$ [37]. The fabricated PMNPs were highly crystalline and the majority of them indicated the sign of magnetite/ hematite NPs, and they could be clearly assigned to the cube shape of metallic iron. The results of XRD analysis showed a series of high characteristic diffraction peaks appearing at $2 \theta=32.5^{\circ}, 35.2^{\circ}, 45.4^{\circ}$, $57.3^{\circ}$ and $62.8^{\circ}$, respectively. The peaks at $2 \theta=35.2^{\circ}$ and $62.8^{\circ}$ mainly indicated the presence of iron oxide. The average diameter of the fabricated PMNPs was also calculated by using Scherres equation as $\mathrm{D}=0.89 \lambda / \beta$. $\cos \theta$, where $\mathrm{D}$ is the average particle size, $\lambda$ is the wavelength of the $\mathrm{CuK} \alpha$ irradiation, $\beta$ belongs to the full width at half maximum intensity of the diffraction peak, and $\theta$ is the diffraction angle at $2 \theta=35.3^{\circ}$ peak of iron oxide NPs [35]. The fabricated PMNPs resulted in the mean crystallite size of $\sim 39 \mathrm{~nm}$. For comparison, the XRD pattern of CSMNPs was also obtained in Fig. 2c). A more or less similar XRD pattern was observed, which also verified that our fabricated PMNPs contained magnetite and hematite of crystalline shapes. In addition, the XRD pattern of PMNPs was also matched with standard data for the pisumsativum peels extract of $\mathrm{Fe}_{3} \mathrm{O}_{4}$ NPs (JCPDS No. 82-1533), and the findings depicted that our fabricated PMNP diffraction peak was overlapping at $2 \theta=35.3^{\circ}$, thereby confirming the formation of $\mathrm{Fe}_{3} \mathrm{O}_{4} \mathrm{NPs}$ [32].

Moreover, SEM analysis was carried out to observe the morphology of fabricated CSMNPs and PMNPs (Fig. 3). Fig. 3c) reveals that PMNPs mainly showed granular homogenous spherical shaped structure of $\mathrm{Fe}_{3} \mathrm{O}_{4}$ (magnetite) with diameter in the range of 30-50 nm. In contrast, CSMNPs were showing chain-like morphology (Fig. 3a). In addition, EDS/X analysis gives qualitative and as well as quantitative status of elements that might be implied in the fabrication of NPs. Fig. 3(b, d) shows that the EDX spectrum contained intense peaks of $\mathrm{Na}$, $\mathrm{Cl}$ and $\mathrm{C}$ in addition to $\mathrm{Fe}$ and $\mathrm{O}$. The $\mathrm{Na}$ and $\mathrm{Cl}$ peaks might have originated from $\mathrm{NaOH}$ and $\mathrm{FeCl}_{2}$ precursors used in the fabrication of PMNPs and CSMNPS. The $\mathrm{C}$ peak in the case of PMNPs was attributed mainly to the polyphenol groups or other carbon-containing biomolecules that were present in the leaf extract (Fig. 7d). The findings revealed that the atomic percentages as obtained by EDX quantification were $\mathrm{Fe}(38.55 \%), \mathrm{C}(5.92 \%), \mathrm{O}(53.58 \%), \mathrm{Na}(1.06 \%)$ and $\mathrm{Cl}$ $(0.90 \%)$ in the case of CSMNPs (Fig. 7b). In contrast, the atomic percentages obtained for PMNPs were $\mathrm{Fe}$ (35.12\%), C (17.12\%), O (45.09\%), $\mathrm{Na}(1.68 \%)$ and $\mathrm{Cl}$ $(0.98 \%)$, which indicated that our fabricated PMNPs were keeping approximately a similar percentage of $\mathrm{Fe}$ and $\mathrm{O}$, as we observed in the case of CSMNPs Fig. 3d). However, the percentages of $\mathrm{C}$ were higher than CSMNPs, which indicated the sign of the involvement of plant bio-molecules in the reduction of metal ions and stabilization of PMNPs (Fig. 3). Moreover, these values might be helpful in observing the atomic content on the surface and near-surface region of the fabricated PMNPs.

\section{Removal Performance and Comparison}

The effects of $\mathrm{CV}$ and EBT concentration were studied over the concentration range of $10-300 \mathrm{mg} / \mathrm{L}$ by keeping the dose constant at $0.500 \mathrm{~g}$ for both CSMNPS 

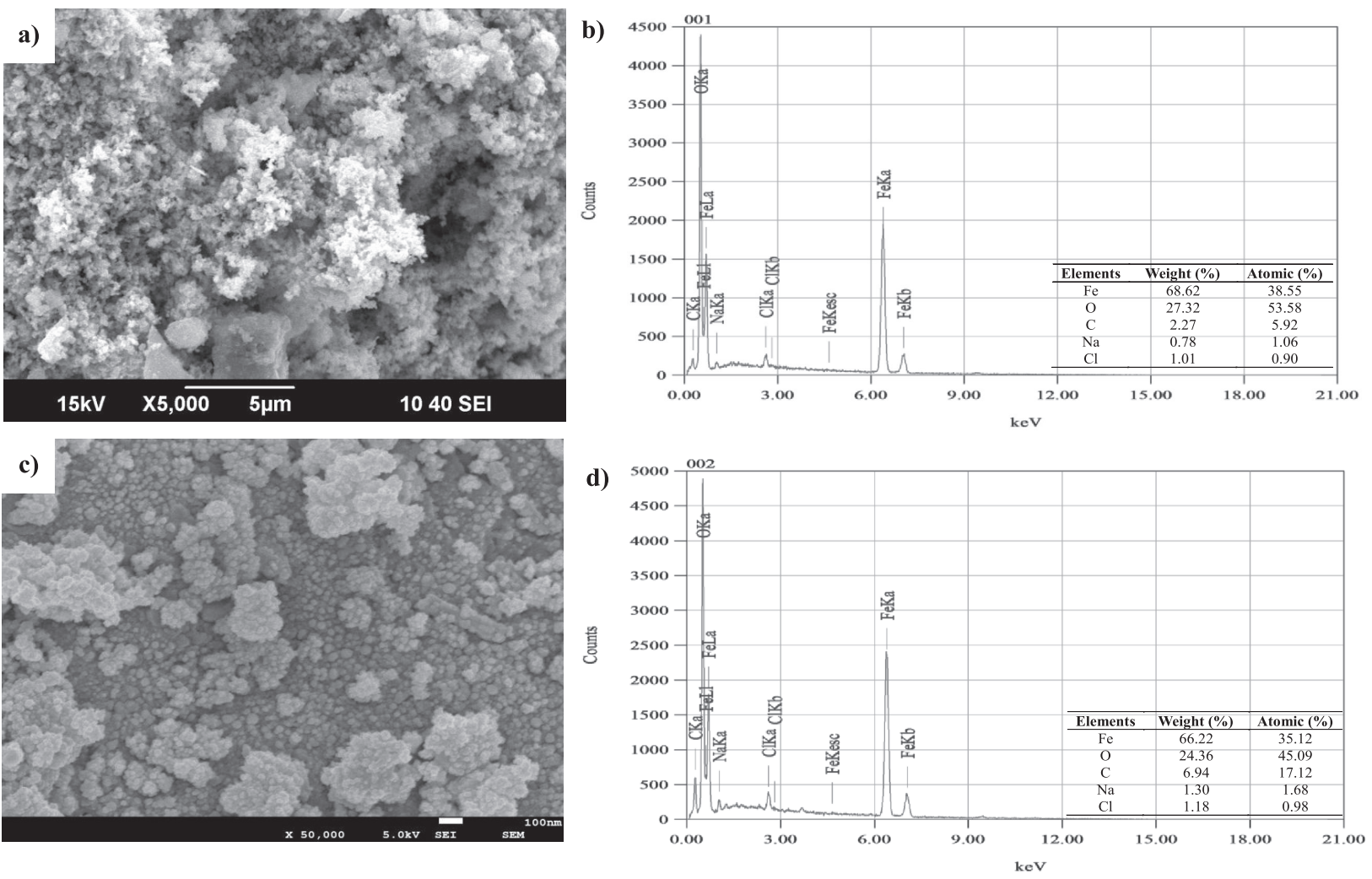

Fig. 3. Scanning electron microscopic (SEM) images and energy-dispersive X-ray (EDX) spectra of a) and b) chemically synthesized magnetic nanoparticles (CSMNPs) and c) and d) phytogenic magnetic nanoparticles (PMNPs).

and PMNPs. Throughout the experiments, the contact time was $540 \mathrm{~min}(9 \mathrm{~h})$ for both dyes. The changes in the concentration of $\mathrm{CV}$ and $\mathrm{EBT}$ at different contact times are shown in Figs 4 and 5. A complete degradation of $\mathrm{CV}$ was observed within $30 \mathrm{~min}$ of contact time for all concentrations, when CSMNPs were used (Fig. 4a). In contrast, a rapid but complete removal of $\mathrm{CV}$ was observed within 10min of contact time when PMNPs were used (Fig. 4b). In the case of EBT, a maximum of $97 \%$ removal efficiency was observed after the contact time of 540min and then it remained constant until the end of the experiment, when CSMNPs were used (Fig. 5a). In contrast, 100\% removal efficiency of EBT was achieved within the first $10 \mathrm{~min}$ of contact time, when PMNPs were used (Fig. 5b). The calculated percentage removal efficiency of the dyes at different concentrations and dosages is given in Table 1, which showed that the removal efficiency of $\mathrm{CV}$ and EBT appeared to be almost $100 \%$ over the entire concentration ranges, in case of PMNPs after contact time of $8 \mathrm{~min}$, which reflects the effectiveness of PMNPs instead of CSMNPs. In contrast, in the case of CSMNPs, the percentage removal efficiency was less than 100 after the contact time of 8 min throughout all concentrations.

The kinetic experimental data were fitted to $1^{\text {st }}$ and $2^{\text {nd }}-$ order rate equations. The equations were prepared by assuming the driving force of degradation to be proportional to the difference between the concentration
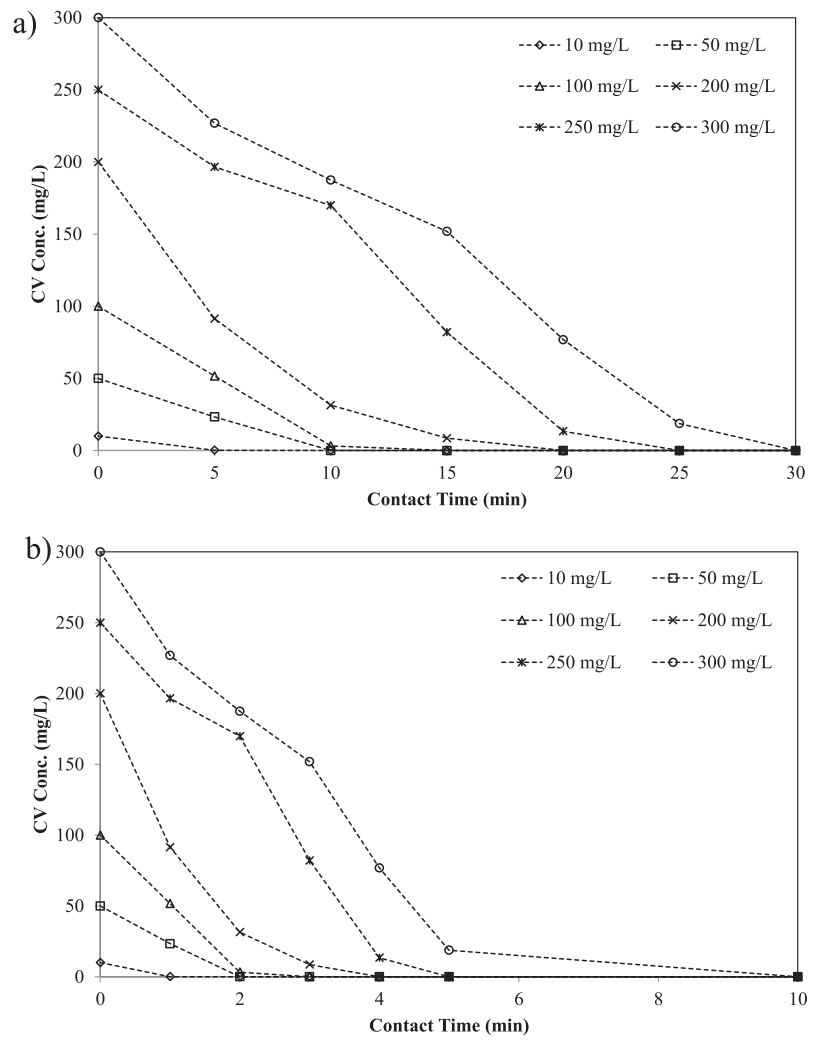

Fig. 4. Influence of contact time on the concentration of crystal violet $(\mathrm{CV})$ at a) dosage: $0.5 \mathrm{~g}$ of chemically synthesized magnetic nanoparticles (CSMNPs); and b) dosage: $0.5 \mathrm{~g}$ of phytogenic magnetic nanoparticles (PMNPs). 
a) 300

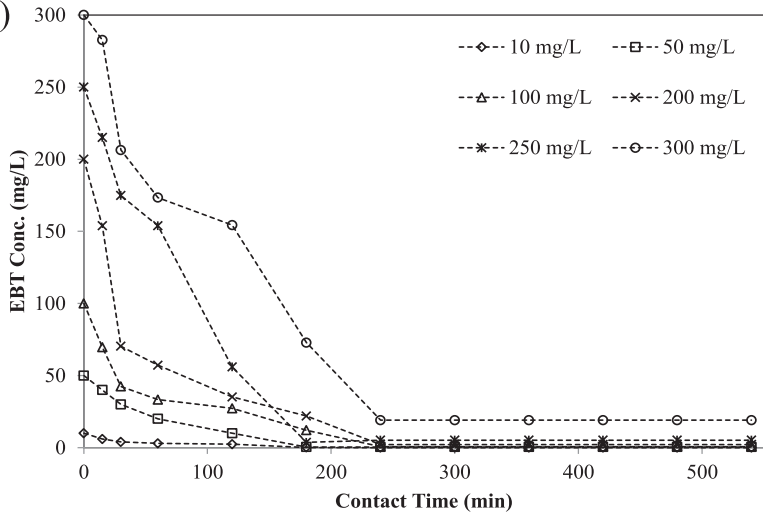

b)

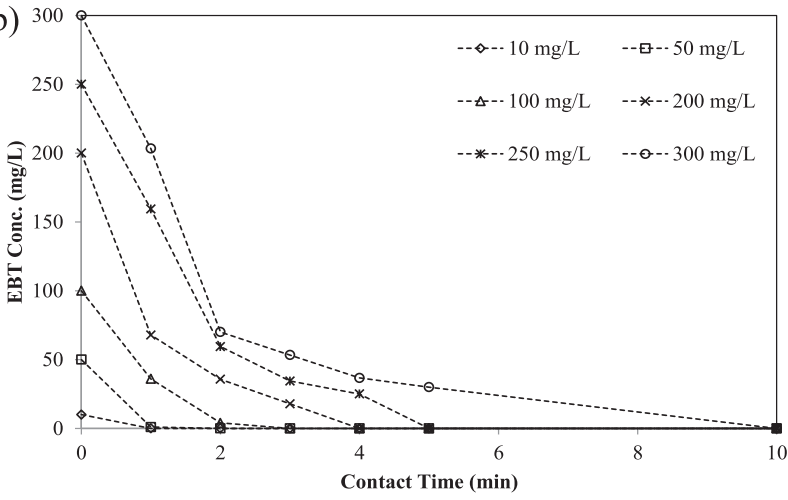

Fig. 5. Influence of contact time on the concentration of Eriochrome black T (EBT) at a) dosage: $0.5 \mathrm{~g}$ of chemically synthesized magnetic nanoparticles (CSMNPs); and b) dosage: $0.5 \mathrm{~g}$ of phytogenic magnetic nanoparticles (PMNPs) of dye $\left(\mathrm{C}_{\text {) }}\right.$ at any time prior to equilibrium and that with equilibrium $\left(\mathrm{C}_{\mathrm{e}}\right)$. Thus, the $1^{\text {st }}$ - and $2^{\text {nd }}$-order rate equations for the removal of solute from aqueous solution might be written as [20]:

Fist-order rate equation

$$
-\frac{d C_{t}}{d t}=k_{1}\left(C_{t}-C_{e}\right)
$$

Second order rate equation

$$
-\frac{d C_{t}}{d t}=k_{2}\left(C_{t}-C_{e}\right)^{2}
$$

... where $\mathrm{C}_{\mathrm{t}}(\mathrm{mg} / \mathrm{L})$ is the dye concentration in solution at time (t) and $\mathrm{C}_{\mathrm{e}}(\mathrm{mg} / \mathrm{L})$ is the dye concentration at equilibrium, and $\mathrm{k}_{1}$ and $\mathrm{k}_{2}$ are the rate constants for the $1^{\text {st }}$ and $2^{\text {nd }}$ equations.

$$
\begin{gathered}
\ln \left(\frac{C_{t}-C_{e}}{C_{o}-C_{e}}\right)=-k_{t} t \\
\frac{1}{C_{t}-C_{e}}-\frac{1}{C_{o}-C_{e}}=k_{2} t
\end{gathered}
$$

...where $\mathrm{C}_{\mathrm{o}}(\mathrm{mg} / \mathrm{L})$ is the initial concentration of the dyes solution.

\begin{tabular}{|c|c|c|c|c|c|c|}
\hline \multirow{3}{*}{ Dye name } & \multicolumn{6}{|c|}{ Initial concentration of aqueous dyes solution (mg/L) } \\
\hline & 10 & 50 & 100 & 200 & 250 & 300 \\
\hline & \multicolumn{6}{|c|}{ Removal efficiency $(\%) \pm 2.5 \%$} \\
\hline \multicolumn{7}{|c|}{ Chemically synthesized magnetic nanoparticles (CSMNPs) } \\
\hline $\mathrm{CV}$ & 97 & 53 & 48 & 45 & 31 & 20 \\
\hline EBT & 60 & 57 & 51 & 47 & 39 & 31 \\
\hline \multicolumn{7}{|c|}{ Phytogenic magnetic nanoparticles (PMNPs) } \\
\hline $\mathrm{CV}$ & 100 & 100 & 100 & 100 & 100 & 93 \\
\hline EBT & 100 & 100 & 100 & 100 & 100 & 90 \\
\hline \multicolumn{7}{|c|}{ Kinetics equilibrium data } \\
\hline \multirow{2}{*}{ Dye name } & \multirow{2}{*}{$\begin{array}{c}\text { Removal efficiency (\%) } \\
\text { at equilibrium }\end{array}$} & \multirow{2}{*}{$\begin{array}{l}\text { Equilibrium time } \\
\text { (min) }\end{array}$} & \multicolumn{2}{|c|}{ First order } & \multicolumn{2}{|c|}{ Second order } \\
\hline & & & $\mathrm{k}\left(\min ^{-1}\right)$ & $\mathrm{R}^{2}$ & $\mathrm{k}(\mathrm{L} / \mathrm{mg} / \mathrm{min})$ & $\mathrm{R}^{2}$ \\
\hline \multicolumn{7}{|c|}{ CSMNPs } \\
\hline $\mathrm{CV}$ & 100 & 30 & 0.01674 & 0.764 & 0.00107 & 0.158 \\
\hline EBT & 97 & 540 & 0.01418 & 0.763 & 0.00023 & 0.044 \\
\hline \multicolumn{7}{|c|}{ PMNPs } \\
\hline $\mathrm{CV}$ & 100 & 10 & 0.01808 & 0.954 & 0.00107 & 0.035 \\
\hline EBT & 100 & 10 & 0.01771 & 0.980 & 0.00158 & 0.009 \\
\hline
\end{tabular}

Table 1. Removal efficiency (\%) of Crystal violet (CV) and Eriochrome black T (EBT) after contact time of 8 min at different initial concentrations; kinetics equilibrium data corresponding to the removal of CV and EBT at initial concentration of $300 \mathrm{mg} / \mathrm{L}$ (dosage: $0.5 \mathrm{~g}$ of chemically synthesized magnetic nanoparticles (CSMNPs) and phytogenic magnetic nanoparticles (PMNPs). 
These equations revealed that they can be used to explain the data corresponding to the pre-equilibrium stage (up to $30 \mathrm{~min}$ for $\mathrm{CV}$ and up to $250 \mathrm{~min}$ for EBT), when CSMNPs were used. On the other hand, up to 10 min time was adjusted for both dyes when PMNPs were employed. The results of linear regression analysis were used to calculate the rate constant for each dye. Table 1 shows the rate constants and corresponding linear correlation coefficient $\left(\mathrm{R}^{2}\right)$ values of $\mathrm{CV}$ and EBT at initial concentration of $300 \mathrm{mg} / \mathrm{L}$, when CSMNPs and PMNPs were used. It can be observed that, according to the $\mathrm{R}^{2}$ values, the degradation of $\mathrm{CV}$ and EBT seems to fit much better to $1^{\text {st }}$-order kinetics than $2^{\text {nd }}$-order for both CSMNPS and PMNPs. Similarly, the rate constant $\left(\mathrm{k}_{1}\right)$ values of $\mathrm{CV}$ and EBT (in the case of PMNPs) were higher than $k_{1}$ values of $\mathrm{CV}$ and EBT (in the case of CMNPs), which indicated faster degradation kinetics of $\mathrm{CV}$ and EBT for PMNPs.

Overall, PMNPs appeared to be more effective than CSMNPs as a catalyst both in term of the extent and speed of dye degradation. The obtained results are summarized in Table 1 for $\mathrm{CV}$ and EBT. However, the $\mathrm{CV}$ degradation was much better than EBT in the case of CSMNPs. At this stage, it was not clear to what extent this could be related to the chemical nature of the CSMNPs or the oxidation state of the iron. Shahwan et al. [20] conducted a similar study for the degradation of methylene blue (MB) and methyl orange (MO) dyes from aqueous solution using green iron nanoparticles fabricated using green tea extract, and their performances were compared with chemically synthesized magnetic nanoparticles. The findings of this study revealed that green iron nanoparticles depicted better degradation performance and kinetics than chemically synthesized magnetic nanoparticles, and almost complete removal of $\mathrm{MB}$ dye was achieved after $200 \mathrm{~min}$ and $350 \mathrm{~min}$ for MO under experimental conditions. Similarly, almost $100 \%$ of MB was removed from solution within the contact time of $30 \mathrm{~min}$ [31]. In another study, 96\% removal efficiency of $\mathrm{MG}$ was observed within the contact time of $60 \mathrm{~min}$ at $50 \mathrm{mg} / \mathrm{L}$ and 298K [33]. Recently, Prasad et al. [32] reported $96 \%$ removal of $\mathrm{MO}$ dye within the contact time of $60 \mathrm{~min}$ at a concentration of $100 \mathrm{mg} / \mathrm{L}$. In comparison, our fabricated PMNPs performed comparatively mush better to degrade CV and EBT within the contact time of $10 \mathrm{~min}$ in the concentration range $10-300 \mathrm{mg} / \mathrm{L}$.

\section{Proposed Removal Mechanism}

Chemical oxidation is often considered a powerful way to remove or degrade toxic and organic pollutants from wastewaters. The oxidation is mainly dependent on the action of hydroxyl radical $\left(\mathrm{OH}^{\bullet}\right)$, which is produced by the traditional Fenton reagent in aqueous solution. Fenton reagent $\left(\mathrm{Fe}^{+2} / \mathrm{H}_{2} \mathrm{O}_{2}\right)$ is basically an amalgamation of $\mathrm{Fe}^{+2}$ ions and $\mathrm{H}_{2} \mathrm{O}_{2}$ in aqueous solution [38]. In the Fenton system, the production of $\left(\mathrm{OH}^{\bullet}\right)$ can be expressed as:

$$
\begin{gathered}
\mathrm{H}_{2} \mathrm{O}_{2}+\mathrm{Fe}^{+2} \rightarrow \mathrm{OH}^{\bullet}+\mathrm{OH}^{-}+\mathrm{Fe}^{+3} \\
\mathrm{OH}^{\bullet}+\mathrm{RH} \rightarrow \mathrm{R}^{\bullet}+\mathrm{H}_{2} \mathrm{O} \\
\mathrm{R}^{\bullet}+\mathrm{Fe}^{+3} \rightarrow \mathrm{R}^{+}+\mathrm{Fe}^{+2} \\
\mathrm{Fe}^{+2}+\mathrm{OH}^{\bullet} \rightarrow \mathrm{Fe}^{+3}+\mathrm{OH}^{-}
\end{gathered}
$$

It can be observed that $\mathrm{Fe}^{+2}$ starts the reaction, leading to the generation of $\mathrm{OH}^{\bullet}$, which further will attack the toxic and organic pollutants leading to their oxidation/degradation. On the other hand, in the Fentonlike system (i.e. $\left.\mathrm{Fe}^{+3} / \mathrm{H}_{2} \mathrm{O}_{2}\right)$, the production of $\left(\mathrm{OH}^{\bullet}\right.$, can be explained as:

$$
\begin{gathered}
\mathrm{H}_{2} \mathrm{O}_{2}+\mathrm{Fe}^{+3} \rightarrow \mathrm{Fe}^{\cdots} \cdot \mathrm{OOH}^{2+}+\mathrm{H}^{+} \\
\mathrm{Fe}^{\cdots} \cdot \mathrm{OOH}^{2+} \rightarrow \mathrm{HO}_{2}^{\bullet}+\mathrm{Fe}^{+2} \\
\mathrm{H}_{2} \mathrm{O}_{2}+\mathrm{Fe}^{+2} \rightarrow \mathrm{OH}^{\bullet}+\mathrm{OH}^{-}+\mathrm{Fe}^{+3} \\
\mathrm{OH}^{\bullet}+\mathrm{RH} \rightarrow \mathrm{R}^{\bullet}+\mathrm{H}_{2} \mathrm{O}
\end{gathered}
$$

It can be seen that $\mathrm{Fe}^{+3}$ initiates the reaction instead of $\mathrm{Fe}^{+2}$, which is being used in traditional Fenton processes and leads to the formation of $\mathrm{Fe} \cdot \cdots \mathrm{OOH}^{2+}$, which further will dissolve and generate $\mathrm{Fe}^{+2}$, and these ferrous ions react with $\mathrm{H}_{2} \mathrm{O}_{2}$ to produce $\mathrm{OH}^{\bullet}$, which further will attack the organic contaminants, leading to their oxidation/ degradation. Numerous studies show that $\mathrm{Fe}_{3} \mathrm{O}_{4}, \mathrm{FeOOH}$ and nZVI can be employed as a source of $\mathrm{Fe}^{+2}$ ions in a Fenton-like process [39]. In addition, these materials are being used to catalyze oxidation of toxic dyes and other organic pollutants [40-43].

In our experiments, PMNPs were shown to contain $\mathrm{Fe}_{3} \mathrm{O}_{4}$. Hence, the sustainability of the $\mathrm{OH}^{\bullet}$ production cycle will depend on the ease of $\mathrm{Fe}^{+2}$ ion availability. In this way, the surface of the $\mathrm{Fe}_{3} \mathrm{O}_{4}$ will first corrode in acidic medium, leading to the generation of $\mathrm{Fe}^{+2}$ ions, which further produce $\mathrm{OH}^{\bullet}$ radicals. Moreover, these generated $\mathrm{OH}^{\bullet}$ radicals then will attack the bonds in the dye molecules, which may be in solution or sorbed on the PMNP surface [44]. In this study, PMNPs showed greater degradation efficiency than CSMNPs if we compare with time. This reason might be explained in the sense that PMNPs had great potential to generate higher amounts of $\mathrm{OH}^{\bullet}$ radicals than CSMNPs at low $\mathrm{pH}$, which was resultant to reducing the time required for complete degradation.

It was also observed that by adding $\mathrm{H}_{2} \mathrm{O}_{2}$ solution to the dye solution, the $\mathrm{pH}$ of the dye solution (containing PMNPs) was reduced to 3.52 (in the case of CV) and 3.41 (in the case of EBT), and it continued to decrease up to 3.04 and 3.01 for CV and EBT, respectively, at the end of the experiments - despite the fact that initially we adjusted dye solution $\mathrm{pH}$ at 6.5 . We calculated $\mathrm{pH}$ at the start and end of the each experiment. Importantly, it has been reported in many studies that if $\mathrm{pH}$ of the solution is less than 4, then the ease of generation of $\mathrm{OH}^{\bullet}$ radicals will increase, thus increasing the degradation efficiency of the Fenton system [45]. In our experiments, the $\mathrm{pH}$ values measured (at the end of the experiments) was less than 4.0, which 

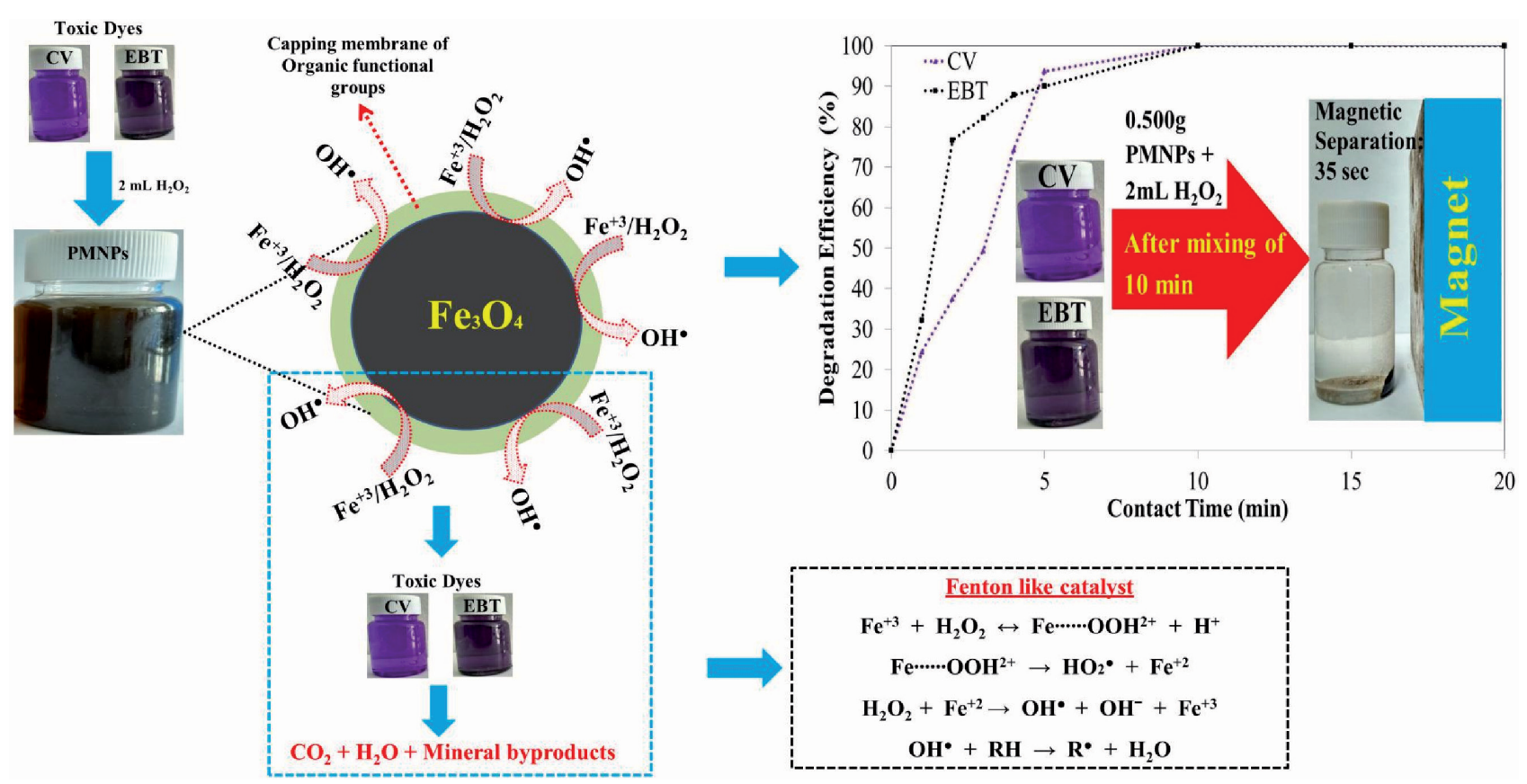

Fig. 6. Proposed removal mechanism of Crystal violet $(\mathrm{CV})$ and Eriochrome black T (EBT) by phytogenic magnetic nanoparticles (PMNPs) in the presence of $2 \mathrm{~mL}(30 \%) \mathrm{H}_{2} \mathrm{O}_{2}$.

was also an important factor for the generation of higher $\mathrm{OH}^{\bullet}$ radicals and reducing the degradation time up-to $10 \mathrm{~min}$ for both dyes. Therefore, in this study, PMNPs were mainly showing a Fenton-like mechanism to degrade toxic and aromatic pollutants under acidic conditions $(\mathrm{pH}<4.0)$ because $\mathrm{Fe}_{3} \mathrm{O}_{4}$ was mainly used as a source of $\mathrm{Fe}^{+2}$ ions to produce $\mathrm{OH}^{\bullet}$ radicals for the oxidation of toxic dyes. Furthermore, the FTIR, XRD and EDX analysis have already verified the presence of iron oxide in PMNPs. The relatively weak and broad peaks in the XRD diagram indicated that PMNPs had amorphous grains, which might be a factor that will assist PMNP dissolution under the acidic medium, and the generation of $\mathrm{Fe}^{+2}$ ions will increase with the decrease
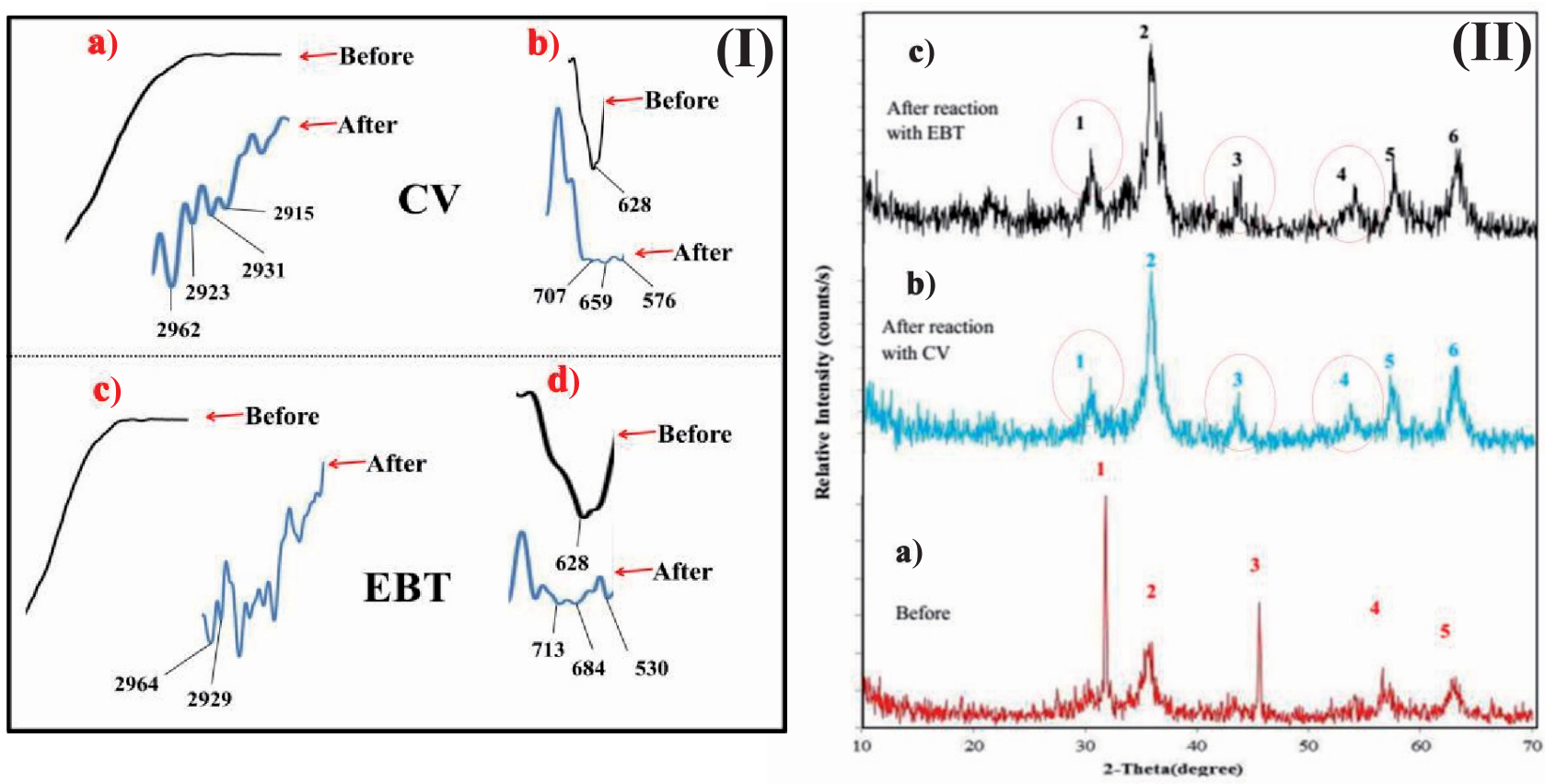

Fig. 7. Fourier transform infrared (FTIR) spectrum of phytogenic magnetic nanoparticles (PMNPs) a) and b) before and after reaction with Crystal violet (CV); c) and (d) before and after reaction with Eriochrome black T (EBT); (II) the powder XRD patterns of a) PMNPs, b) after reaction with $\mathrm{CV}$ and c) after reaction with EBT. 
in $\mathrm{pH}$. It is also worth mentioning that the reusability of the PMNPs was greatly damaged by adding $\mathrm{H}_{2} \mathrm{O}_{2}$ solution into the dye solution because capping of plant bio-molecules disappeared due to the action of $\mathrm{OH}^{\bullet}$ radicals. This phenomenon is also supporting the fact that $\mathrm{Fe}_{3} \mathrm{O}_{4}$ was corroded from the surface of PMNPs, which further was employed in the generation of $\mathrm{OH}^{\bullet}$ radicals leading to the degradation of toxic dyes (Fig. 6).

\section{Fourier Transforms Infrared Spectroscopic (FTIR) and Powder X-ray Diffraction (XRD) Analyses}

The FTIR spectra were also studied after the degradation reaction of $\mathrm{CV}$ and EBT dyes. The FTIR profile obtained after the reaction with $\mathrm{CV}$ and EBT showed prominent spectral attributes in the range of 296 to $2915 \mathrm{~cm}^{-1}$ (Fig. 7(I)). These peaks were mainly associated to the stretching vibration of $-\mathrm{CH}_{3}$ and $\mathrm{C}-\mathrm{H}$ of the methyl groups, created from $\mathrm{CV}$ and EBT and/or its products sorbed on the surface of PMNPs. Moreover, other peaks also appeared in the range of $713-530 \mathrm{~cm}^{-1}$, which were related to $-\mathrm{C}-\mathrm{S}$ - stretching vibration (Fig. 7(I)). These peaks were also showing that the degradation products were sorbed or attached to the surface of PMNPs. Similarly, the XRD pattern was also studied after the reaction with CV and EBT. The results clearly indicated that new peaks originated at $2 \theta=30^{\circ}, 44.2^{\circ}$ and $57.2^{\circ}$, in addition to other subsisted peaks (Fig. 7(II)). While the intensities of remaining peaks were increased slightly and expanded, this indicates the dissolution of PMNPS under acid attack (Fig. 7(II)). The occurrence of new peaks and increments in the intensities might be an indication of degradation by PMNPs. In addition, the concentration of total organic carbon (TOC) and total nitrogen (TN) was also simultaneously measured by combining the Shimadzu total organic carbon analyzer (TOC-V, Shimadzu Scientific Instruments, Inc., USA) and the TN measurement unit (TNM-1, Shimadzu Scientific Instruments, Inc., USA) before and after adding PMNPs from both dye solutions. It was noticed that initially the concentration of TOC and TN was $48.5 \pm 2$ and $86.26 \pm 2 \mathrm{mg} / \mathrm{L}$, respectively, in both dye solutions. Later, it was significantly dropped (from $48.5 \pm 2$ to $1.58 \pm 1.5 \mathrm{mg} / \mathrm{L}$ for TOC and $86.26 \pm 2$ to $3.5 \pm 1.8 \mathrm{mg} / \mathrm{L}$ for TN) after adding PMNPs and $\mathrm{H}_{2} \mathrm{O}_{2}$ in both dye solutions.

\section{Conclusions}

Overall, to the best of our knowledge, for the first time innovative PMNPs were produced by employing a non-toxic, cheap and environmental friendly "green" recipe using leaf extract of $F$. chinensis Roxb as reducing and capping agent. The developed methods did not require any additional toxic or hazardous chemicals and can be scaled up to bulk level. The formation of PMNPs was characterized with the help of different techniques, i.e., UV-visible spectra, FTIR, powder XRD, SEM and EDX. The FTIR analysis depicted the presence of plant bio-molecules (polyphenols, carboxyl, reducing sugars, flavonoids and organic acids) in the leaf extract, which were responsible for the bio-reduction of metal ions and the stabilization of PMNPs. Furthermore, the powder XRD analysis results confirmed the presence of iron oxide or magnetite $\left(\mathrm{Fe}_{3} \mathrm{O}_{4}\right)$ NPs having crystalline cube shape of metallic iron. Similarly, SEM analysis indicated that PMNPs mainly showed granular homogenous porous sphericalshaped structure of $\mathrm{Fe}_{3} \mathrm{O}_{4}$ (magnetite) with diameter in the range of 30-50 nm. In addition, EDX results showed the presence of higher percentages of carbon, which clearly indicated the sign of the involvement of plant bio-molecules in the reduction of metal ions and stabilization of PMNPs. Furthermore, the results indicated that our fabricated PMNPs demonstrated impressive removal capabilities and the kinetics compared to CSMNPs in the presence of $\mathrm{H}_{2} \mathrm{O}_{2}$ for toxic dyes (CV and EBT) from aqueous solutions and acted as a Fenton-like catalyst. A complete $100 \%$ degradation efficiency of $\mathrm{CV}$ and EBT was achieved within the contact time of $10 \mathrm{~min}$ and the kinetic experimental data fit well with the first-order degradation rate equation for both dyes. Altogether, the developed "green" recipe can easily be implemented to produce potentially biocompatible and non-toxic magnetic nanoparticles for wastewater treatment.

\section{Acknowledgements}

This work was supported by the State Key Laboratory of Environmental Criteria and Risk Assessment (No. SKLECRA 2013FP12) and Shandong Province Key Research and Development Program (2016GSF115040). The first author would like to thank the Chinese Scholarship Council (CSC No. 2016GXYO20) for its financial support.

\section{Conflict of Interest}

The authors declare no conflict of interest.

\section{References}

1. ALI I., KHAN Z.M., SULTAN M., MAHMOOD M.H., FARID H.U., ALI M., NASIR A. Experimental Study on Maize Cob Trickling Filter-Based Wastewater Treatment System: Design, Development, and Performance Evaluation. Pol. J. Environ. Stud. 25 (6), 2265, 2016.

2. ALI I., PENG C., NAZ I., KHAN Z.M., SULTAN M., ISLAM T., ABBASI I.A. Phytogenic magnetic nanoparticles for wastewater treatment: a review. RSC Adv. 2017, 7, 40158, 2017a.

3. ALI I., PENG C., KHAN Z.M., NAZ I. Yield cultivation of magnetotactic bacteria and magnetosomes: A review. J. Basic Microbiol. 9999, 1, 2017b. 
4. ALI I., KHAN Z.M., PENG C., NAZ I., SULTAN M., ALI M., MAHMOOD M.H., NIAZ Y. Identification and Elucidation of the Designing and Operational Issues of Trickling Filter Systems for Wastewater Treatment. Pol. J. Environ. Stud. 26 (6), 2431, 2017c.

5. FARID H.U., BAKHSH A., ALI M.U., MAHMOODKHAN Z., SHAKOOR A., ALI I. Field investigation of aquifer storage recovery (ASR) technique to recharge groundwater: a case study in Punjab province of Pakistan. Water Sci. Tech-W. Sup.p.ws 2017083, 2017.

6. PUNRATTANASIN P., SARIEM P. Adsorption of copper, zinc, and nickel using loess as adsorbents. Pol. J. Environ. Stud. 24, 1259, 2015.

7. SUROVKA D., PERTILE E. Sorption of Iron, Manganese, and Copper from Aqueous Solution Using Orange Peel: Optimization, Isothermic, Kinetic, and Thermodynamic Studies. Pol. J. Environ. Stud. 26 (2), 795, 2017.

8. TĂNASE A.M., CHICIUDEAN I., MEREUȚĂ I., IONESCU R., CORNEA C.P., VASSU T., STOICA I. Microbial Community Dynamics in Field-Scale Biopile Bioremediation. Pol. J. Environ. Stud. 26 (1), 331, 2017.

9. PALIULIS D. Removal of formaldehyde from synthetic wastewater using natural and modified zeolites. Pol. J. Environ. Stud. 25 (1), 251, 2017.

10. VAKILI M., RAFATULLAH M., SALAMATINIA B., ABDULLAH A.Z., IBRAHIM M.H., TAN K.B., GHOLAMI Z.,AMOUZGAR P. Application of chitosan and its derivatives as adsorbents for dye removal from water and wastewater: A review. Carbohydr. Polym. 113, 115, 2014.

11. YAGUB M.T., SEN T.K., AFROZE S., ANG H.M. Dye and its removal from aqueous solution by adsorption: a review. Adv. Colloid Interface Sci. 209, 172, 2014.

12. CRINI G. Non-conventional low-cost adsorbents for dye removal: a review. Bioresour. Technol. 97 (9), 1061, 2006.

13. SIVARAJ R., NAMASIVAYAM C., KADIRVELU K. Orange peel as an adsorbent in the removal of acid violet 17 (acid dye) from aqueous solutions. Waste management, 21 (1), 105, 2001.

14. LAKSHMI U.R., SRIVASTAVA V.C., MALL I.D., LATAYE D.H. Rice husk ash as an effective adsorbent: Evaluation of adsorptive characteristics for Indigo Carmine dye. J. Environ. Manag. 90 (2), 710, 2009.

15. GONG R., DING Y., LI M., YANG C., LIU H.,SUN Y. Utilization of powdered peanut hull as biosorbent for removal of anionic dyes from aqueous solution. Dyes Pigm. 64 (3), 187, 2005.

16. NAMASIVAYAM C., KUMAR M.D., SELVI K., BEGUM R.A., VANATHI T., YAMUNA R.T. 'Waste'coir pith - a potential biomass for the treatment of dyeing wastewaters. Biomass Bioenergy.21 (6), 477, 2001.

17. PORKODI K., KUMAR K.V. Equilibrium, kinetics and mechanism modeling and simulation of basic and acid dyes sorption onto jute fiber carbon: Eosin yellow, malachite green and crystal violet single component systems. J. Hazard. Mater. 143 (1), 311, 2007.

18. SIVASHANKAR R., SATHYA A.B., VASANTHARAJ K., SIVASUBRAMANIAN V. Magnetic composite an environmental super adsorbent for dye sequestration - A review. ENMM. 1, 36, 2014.

19. LUO X., ZHANG L. High effective adsorption of organic dyes on magnetic cellulose beads entrapping activated carbon. J. Hazard. Mater. 171 (1), 340, 2009.

20. SHAHWAN T., SIRRIAH S.A., NAIRAT M., BOYACI E., EROĞLU A.E., SCOTT T.B.,HALLAM K.R. Green synthesis of iron nanoparticles and their application as a Fenton-like catalyst for the degradation of aqueous cationic and anionic dyes. Chem. Eng. J. 172 (1), 258, 2011.

21. SU C. Environmental implications and applications of engineered nanoscale magnetite and its hybrid nanocomposites: A review of recent literature. J. Hazard. Mater. 322, 48, 2017.

22. SHAMAILA S., SAJJAD A.K.L., FAROOQI S.A., JABEEN N., MAJEED S., FAROOQ I. Advancements in nanoparticle fabrication by hazard free eco-friendly green routes. Appl. Mater. Today. 5, 150, 2016.

23. MYSTRIOTI C., SPARIS D., PAPASIOPI N., XENIDIS A., DERMATAS D., CHRYSOCHOOU M. Assessment of polyphenol coated nano zero valent iron for hexavalent chromium removal from contaminated waters. Bull. Environ. Contam. Toxicol. 94, 302, 2015.

24. FAZLZADEH M., RAHMANI K., ZAREI A., ABDOALLAHZADEH H., NASIRI F., KHOSRAVI R. A novel green synthesis of zero valent iron nanoparticles (NZVI) using three plant extracts and their efficient application for removal of $\mathrm{Cr}$ (VI) from aqueous solutions. Adv. Powder Technol. 28, 122, 2017.

25. GUPTA V.K., NAYAK A. Cadmium removal and recovery from aqueous solutions by novel adsorbents prepared from orange peel and $\mathrm{Fe}_{2} \mathrm{O}_{3}$ nanoparticles. Chem. Eng. J. 180, 81, 2012.

26. LINGAMDINNE L.P., CHANG Y.Y., YANG J.K., SINGH, J., CHOI E.H., SHIRATANI M., ATTRI P. Biogenic reductive preparation of magnetic inverse spinel iron oxide nanoparticles for the adsorption removal of heavy metals. Chem. Eng. J. 307, 74, 2017.

27. MARTÍNEZC M., LÓPEZG M., BARRIADA J.L., HERRERO R., VICENTE M.E.S. Green synthesis of iron oxide nanoparticles. Development of magnetic hybrid materials for efficient As (V) removal. Chem. Eng. J. 301, 83, 2016.

28. PRASAD K.S., GANDHI P.,SELVARAJ K. Synthesis of green nano iron particles (GnIP) and their application in adsorptive removal of As (III) and As (V) from aqueous solution. Appl. Surf. Sci. 317, 1052, 2014.

29. VENKATESWARLU S., KUMAR B.N., PRATHIMA B., SUBBARAO Y., JYOTHI N.V.V. A novel green synthesis of $\mathrm{Fe}_{3} \mathrm{O}_{4}$ magnetic nanorods using Punica Granatum rind extract and its application for removal of $\mathrm{Pb}(\mathrm{II})$ from aqueous environment. Arab. J. Chem. 2014.

30. VENKATESWARLU S., LEE D., YOON M. Bioinspired 2D-Carbon Flakes and $\mathrm{Fe}_{3} \mathrm{O}_{4}$ Nanoparticles Composite for Arsenite Removal. ACS Appl. Mater. Interfaces. 8 (36), 23876, 2016.

31. BUAZAR F., BAGHLANIN M.H., BADRI M., KASHISAZ M., KHALEDIN A., KROUSHAWI F. Facile one pot phytosynthesis of magnetic nanoparticles using potato extract and their catalytic activity. Starch/Staerke. 68 (7-8), 796, 2016.

32. PRASAD C., YUVARAJA G., VENKATESWARLU P. Biogenic synthesis of $\mathrm{Fe}_{3} \mathrm{O}_{4}$ magnetic nanoparticles using Pisumsativum peels extract and its effect on magnetic and Methyl orange dye degradation studies. J. Magn. Magn. Mater. 424, 376, 2017.

33. WENG X., HUANG L., CHEN Z., MEGHARAJ M., NAIDU R. Synthesis of iron-based nanoparticles by green tea extract and their degradation of malachite. Ind. Crops Prod. 51, 342, 2013.

34. ALI I., PENG C., YE T., NAZ I. Sorption of cationic malachite green dye on phytogenic magnetic nanoparticles functionalized by 3-marcaptopropanic acid. RSC Adv. 8, 8878,2018 
35. WEI Y., FANG Z., ZHENG L.,TSANG E.P. Biosynthesized iron nanoparticles in aqueous extracts of Eichhorniacrassipes and its mechanism in the hexavalent chromium removal. Appl. Surf. Sci. 399, 322, 2017.

36. SMULEAC V., VARMA R., SIKDAR S., BHATTACHARYYA D. Green synthesis of Fe and Fe/ Pd bimetallic nanoparticles in membranes for reductive degradation of chlorinated organics. J. Membr. Sci. 379 (1), 131, 2011.

37. NASRAZADANI S., NAMDURI H. Study of phase transformation in iron oxides using laser induced breakdown spectroscopy. Spectrochim. Acta B Atomic Spectrosc.61 (5), 565, 2006.

38. MOON B.H., PARK Y.B.,PARK K.H. Fenton oxidation of Orange II by pre-reduction using nanoscale zero-valent iron. Desalination. 268 (1), 249, 2011.

39. XUE X., HANNA K.,DENG N. Fenton-like oxidation of Rhodamine $\mathrm{B}$ in the presence of two types of iron (II, III) oxide. J. Hazard. Mater. 166 (1), 407, 2009.
40. SHIN S., YOON H., JANG J. Polymer-encapsulated iron oxide nanoparticles as highly efficient Fenton catalysts. Catal. Commun. 10 (2), 178, 2008.

41. XU L., WANG J. A heterogeneous Fenton-like system with nanoparticulate zero-valent iron for removal of 4-chloro-3methyl phenol. J. Hazard. Mater. 186 (1), 256, 2011.

42. SHU H.Y., CHANG M.C., CHEN C.C., CHEN P.E. Using resin supported nano zero-valent iron particles for decoloration of Acid Blue 113 azo dye solution. J. Hazard. Mater. 184 (1), 499, 2010.

43. KALLEL M., BELAID C., MECHICHI T., KSIBI M., ELLEUCH B. Removal of organic load and phenolic compounds from olive mill wastewater by Fenton oxidation with zero-valent iron. Chem. Eng. J. 150 (2), 391, 2009.

44. WATTS R.J., FOGET M.K., KONG S.H., TEEL A.L. Hydrogen peroxide decomposition in model subsurface systems. J. Hazard. Mater. 69 (2), 229, 1999.

45. KUO W.G. Decolorizing dye wastewater with Fenton's reagent. Water Res. 26 (7), 881, 1992. 